\title{
Co-op Employer Evaluation of the Graduate AtTributes: A Comparison of TWO APPROACHES
}

\author{
Margaret L. Gwyn and Rishi Gupta \\ University of Victoria \\ mgwyn@uvic.ca and guptar@uvic.ca
}

\begin{abstract}
Cooperative education (co-op) is an important and mandatory part of undergraduate engineering at the University of Victoria (UVic). Because of this close integration with the curriculum, the Faculty of Engineering has chosen to use co-op employer evaluations of students as part of the assessment of the $C E A B$ graduate attributes. This paper will describe the two employer surveys currently in use at UVic: one administered by the university's co-op office and repurposed for attribute assessment; and a second, possibly unique in Canada, designed expressly for employer assessment of the attributes. Results are presented from each, showing our employers tend to rank students highly in attributes such as Knowledge Base, Ethics and Equity, and Life-Long Learning, but lower in Economics and Project Management. When results from the two surveys are combined, we find systematic differences between the responses from the two tools. We conclude that caution is needed when combining results from different assessment tools.
\end{abstract}

Keywords: Co-operative Education; Graduate Attributes; Outcomes Assessment; Accreditation

\section{INTRODUCTION}

Co-op is an integrated and mandatory part of the undergraduate engineering curriculum at UVic. Every engineering student must complete at least 16 months of co-op work terms as part of their degree requirements. Our co-op employers are invaluable instructors, teaching our students vital real-world skills. Therefore, when the Canadian Engineering Accreditation Board (CEAB) moved to an outcomes-based assessment model for accreditation, it was obvious that we must include employers' assessment of our students in our plan.

Other Canadian engineering schools have also explored the idea of using co-op and employers in attribute assessment. Dalhousie and Memorial Universities have integrated graduate attribute assessment into the on-campus portion of their co-op curriculum ([6], [2]). The University of Manitoba has talked to postgraduation employers of their students to gather assessment data ([4]), and the University of Waterloo has taken an existing tool that gathers co-op employer evaluations for co-op work term marking purposes and repurposed it for graduate attribute assessment ([5]).

At UVic, we have taken a two-pronged approach. Much like the University of Waterloo, our university's coop office already has a survey in place that all co-op employers complete about their students. We collect and use this data, but we also have designed our own purposemade survey to collect information from co-op employers specifically about graduate attributes. Both these tools measure employers' perceptions of our students. This is a form of indirect assessment, which is an important compliment to the more traditional forms of direct assessment ([1]).

In this paper we will present the two employer surveys in use at the University of Victoria. We will describe the similarities and differences of the two tools and present some sample results from each. Finally, we will discuss the challenges of combining the information from these tools.

\section{THE TWO TOOLS}

\subsection{The Last Co-op Employer Survey}

The Last Co-op Employer Survey (LCES) was designed by MG in 2014, based on a tool developed at Dalhousie University ([3]). The aim was to create a tool that would be simple to administer and would gather data on all attributes and indicators from all employers.

Very simply, the LCES goes through each attribute, lists a set of indicators for each, and asks the employers to rate the extent to which their student has demonstrated each behavior. The employers are also asked to rate the extent to which the current work term has contributed to their student's development in each attribute, and space is provided for comments on each attribute and on the survey overall. The survey is done online and a sample may be viewed at http://fluidsurveys.com/s/LCES/.

Each term, the Engineering and Computer Science/Math Co-op and Career Office provides us with a list of all employers currently supervising engineering students. To identify employers of students who are 
nearing graduation, we select only those employers with students who are on work term $\# 4$ or higher. In the last month of each term, these employers are invited by email to complete the survey. The email explains the information is being used for accreditation purposes and gives a link to the online survey. Different links are provided based on the program in which the employer's student is enrolled. This allows separation of responses by program; otherwise, no identifying information is collected about the employers or their students.

The results from the survey, including any comments, are forwarded to each program in the following term. This allows individual programs to not only track student performance, but also to identify attributes that need attention and take corrective measures in the curriculum or via changes in individual courses.

\subsection{The Co-op Competency Assessment Tool}

The Co-op Competency Assessment Tool (CCAT) was launched by UVic's Co-operative Education Program and Career Services Office in 2012 to assess student learning during work terms. It is based on 10 core competencies that they defined as traits that every UVic co-op student should be expected to develop ([7]). The CCAT also includes program-specific competencies, but information collected about these competencies unfortunately cannot yet be included in the reports generated by the software package in use.

Based on the definitions of the competencies, we have developed a mapping between the core competencies and our attributes and indicators: seven of the core competencies map to seven different attributes; two map to an eighth attribute; and the remaining competency does not map to any attribute.
The CCAT is done online by every UVic co-op student and their respective employer in each of their work terms. At the beginning of the work term, the student selfassesses themselves in all 10 core competencies, and works with their employer to choose at least three competencies to focus on during the work term. In the middle and again at the end of the work term, the student self-assesses their own progress in the three chosen competencies plus any other competencies of their choice. After the student has completed their assessments, an automatically generated email is sent to their employer. The employer can then access and read the students' selfassessments, and add their own assessments.

Students are expected to read their employers' assessment. Co-op coordinators discuss the initial and mid-term assessment with the student and their employer during the work-site visit, and all three assessments with the student before they apply to their next work term.

Each term, the Co-operative Education Program and Career Services Office provides the Office of the Associate Dean Undergraduate Programs, Faculty of Engineering with the raw data file of CCAT results for all engineering students who did co-op placements during the previous term. The assessments of students who were on work term \#4 or higher are selected, the results are divided by program, and the competencies that map to the attributes are pulled out. The analyzed data is then sent to each program.

\subsection{Comparing the tools}

The LCES and the CCAT, while both surveying co-op employers, are very different tools. In Table 1, we compare the two tools in several key aspects.

Table 1: A comparison of the LCES and the CCAT

\begin{tabular}{|c|c|c|}
\hline Aspect & CCAT & LCES \\
\hline Purpose of assessment & $\begin{array}{c}\text { To assess students' learning during work } \\
\text { terms }\end{array}$ & $\begin{array}{c}\text { To improve program curriculum and } \\
\text { maintain accreditation }\end{array}$ \\
\hline Administered by & $\begin{array}{c}\text { Co-operative Education Program and Career } \\
\text { Services Office }\end{array}$ & $\begin{array}{l}\text { Office of the Associate Dean Undergraduate } \\
\text { Programs, Faculty of Engineering }\end{array}$ \\
\hline Number of terms in use & 9 & 4 \\
\hline $\begin{array}{c}\text { Number of employers } \\
\text { surveyed since inception }\end{array}$ & $\begin{array}{c}\text { 7067, of which } 2272 \text { were employers of } \\
\text { engineering students }\end{array}$ & 286 \\
\hline Response rate & Very close to $100 \%$ & $\sim 32 \%$ \\
\hline Workload for employer & $\begin{array}{l}\text { Accepted and mandatory part of the co-op } \\
\text { process }\end{array}$ & New, additional, and optional request \\
\hline Level of anonymity & None & Almost complete \\
\hline Coverage of attributes & Sparse & Complete \\
\hline $\begin{array}{c}\text { Can be used to track } \\
\text { students' development? }\end{array}$ & $\begin{array}{l}\text { Yes; employers of students on all work } \\
\text { terms are surveyed }\end{array}$ & $\begin{array}{c}\text { No; only employers of students on final } \\
\text { work terms are surveyed. }\end{array}$ \\
\hline $\begin{array}{c}\text { Can be refined/revised by } \\
\text { Engineering? }\end{array}$ & No & Yes \\
\hline Workload for Engineering & Minimal & High \\
\hline
\end{tabular}




\section{SAMPLE RESULTS}

In this section, we will present some general results from the LCES and CCAT. For each survey, we started by combining the responses from employers of students in our four established programs: Computer, Electrical, Mechanical and Software Engineering. Although UVic offers two more engineering programs, the Civil and Biomedical programs do not yet have graduating students, and so we cannot yet include comparable data for them. Next we pooled all the responses gathered over the three academic terms of 2014.

As the sample survey referred to in Section 2.1 shows, the LCES asks employers to rate the extent to which their student demonstrates each behavior on a four point scale: Rarely, Sometimes, Usually, or Always. We assigned these four choices the numerical values of $0-3$. In the CCAT, the employers are asked to assess their students' level of proficiency by choosing one of Beginning, Developing, Accomplished or Exemplary; we similarly assigned these the numerical values of $0-3$. Using these numerical scales, we calculated the average response for 2014 over all programs for each question on each survey.

Note our choice to start the numerical scale at 0 rather than 1. This is deliberate: when the lowest possible bin of a response distribution is assigned the value of 1 , as is often done, the results that are reported can be misleading. For example, if we numbered our response choices $1-4$ and reported an average response of 2 , many readers would interpret that result as $2 / 4$, or $50 \%$. However, in this numbering system, no result can be lower than 1: an average response of 2 should rather be interpreted as $33 \%$. Renumbering the response choices to $0-3$ puts our hypothetical average response at 1 , and makes the intuitive interpretation of $1 / 3$ correct.

For the LCES, we finally took the average response for the 3-5 behaviours associated with each attribute and averaged them to arrive at a three-term, all program average for each attribute.

For the CCAT, our mapping of competencies usually had only one competency associated with a given attribute, so this final averaging was not needed. The exception is Lifelong Learning: two competencies mapped to different aspects of Lifelong Learning, so we averaged the average responses of those two competencies.

Figure 1 shows our results - the 2014 average response by attribute over all programs for the LCES and the CCAT.

\section{DISCUSSION}

Looking first at the LCES results in Fig. 1, we can see our co-op employers rate our students highly in the attributes of Knowledge Base, Ethics and Equity, and Life-long Learning. The lowest ratings are found for the attribute of Economics and Project Management.

The CCAT results also show low ratings for Economics and Project Management. When it comes to the most highly rated attributes, the CCAT does not have a question mapping to the Knowledge Base attribute. The questions that map to Ethics and Equity and Life-long

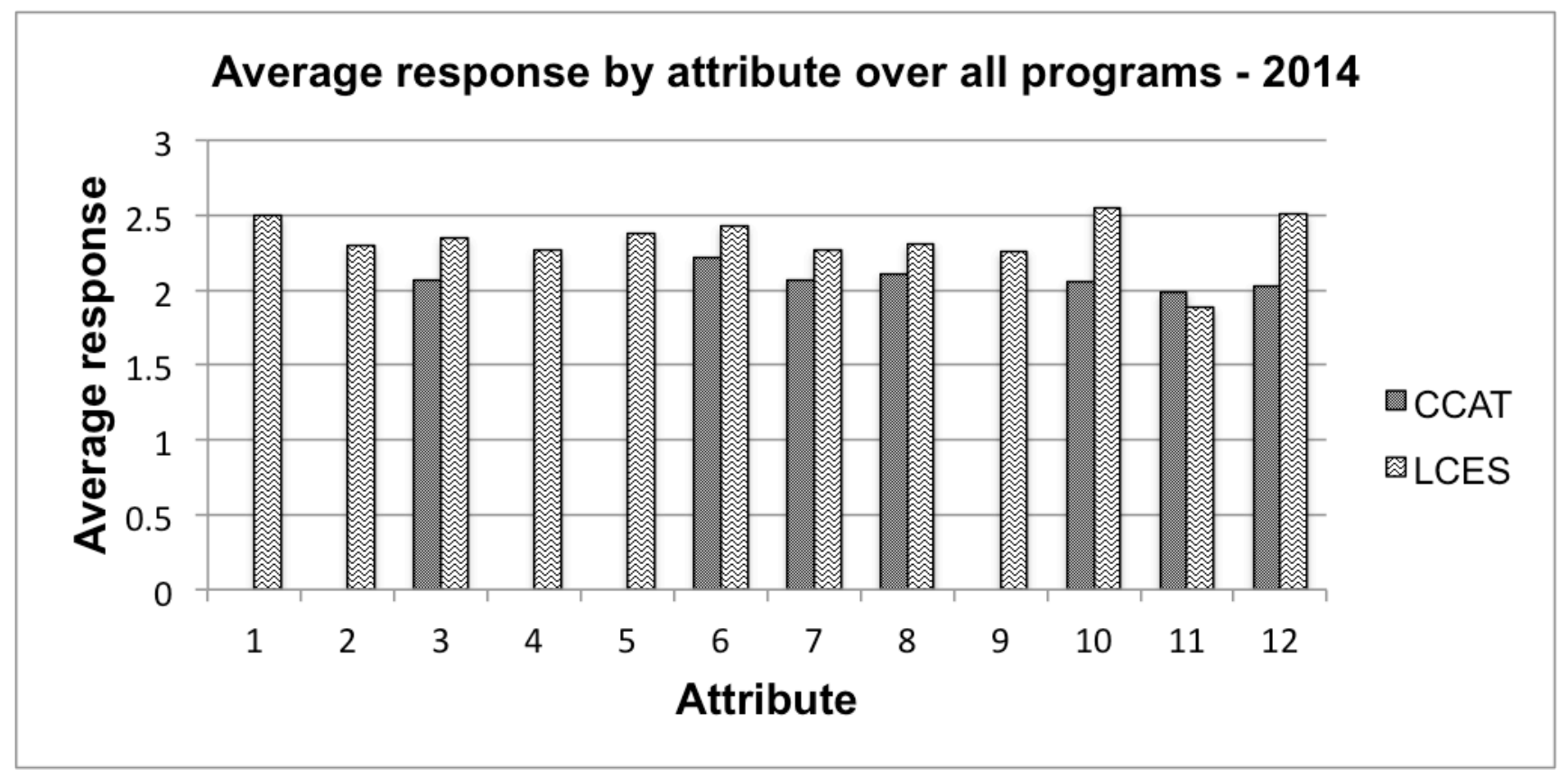

Fig. 1. Sample results of the CCAT and the LCES 
a

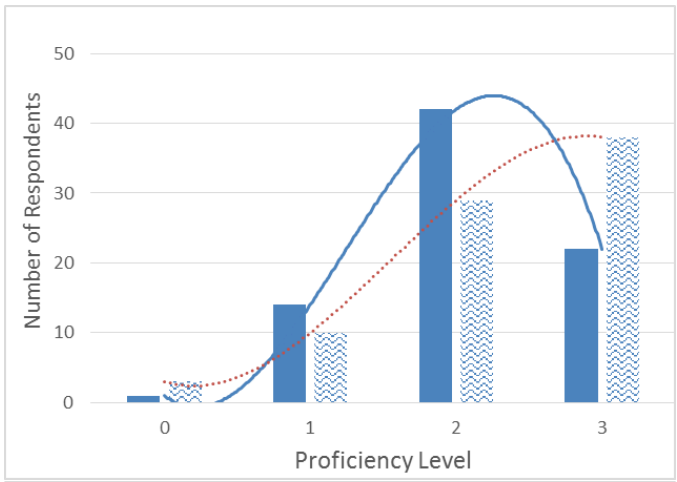

c

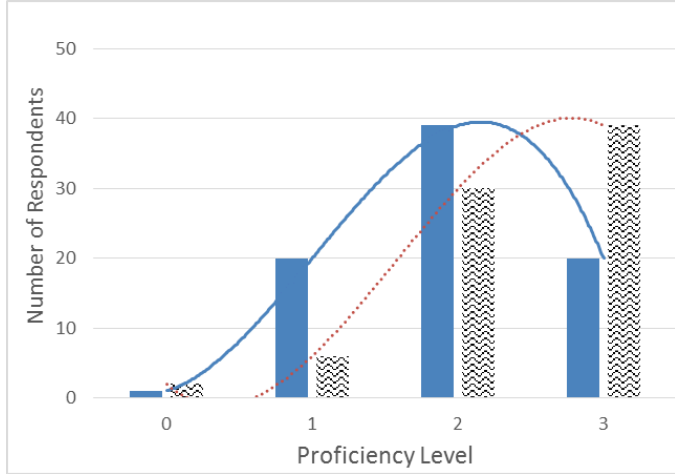

e

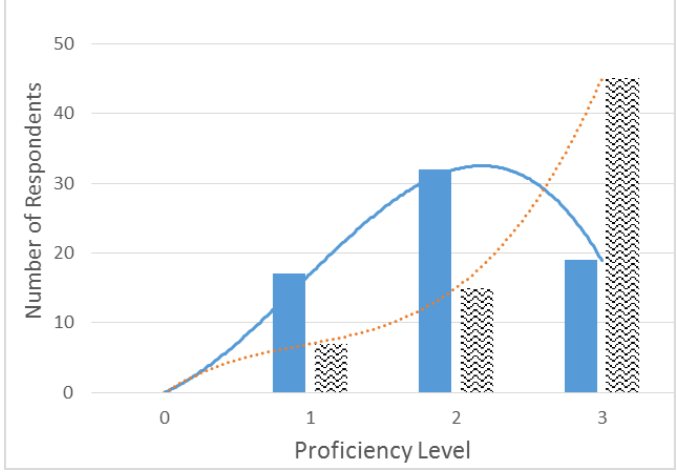

g

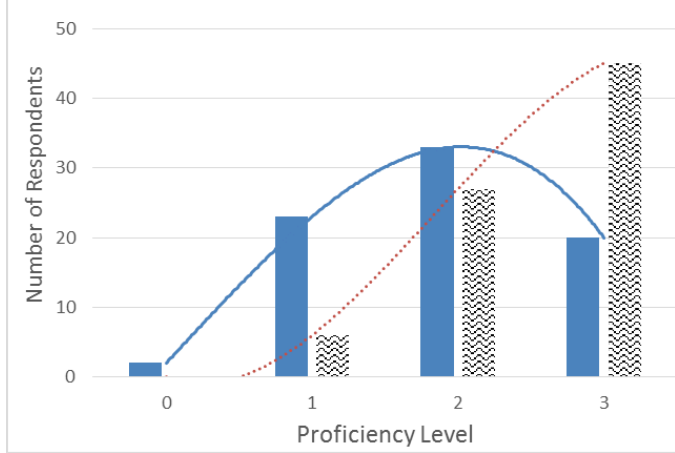

b

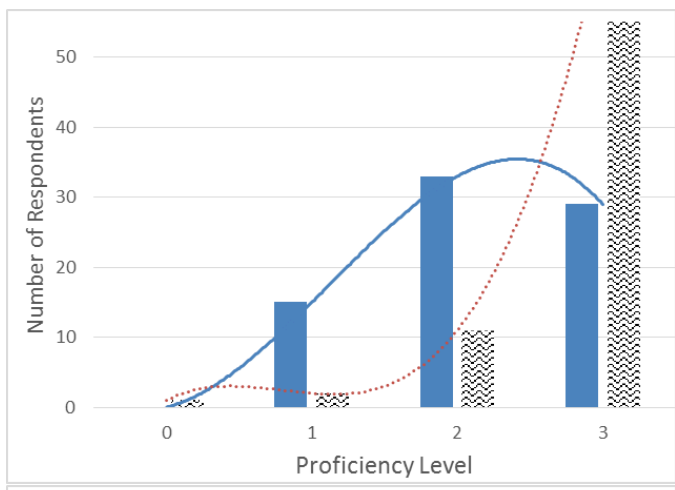

d

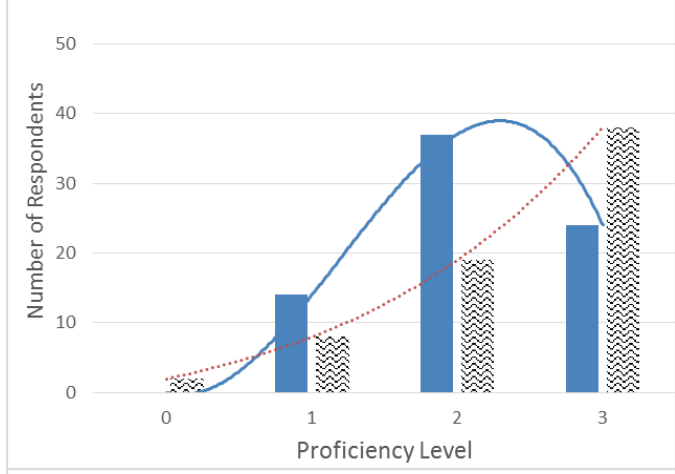

f

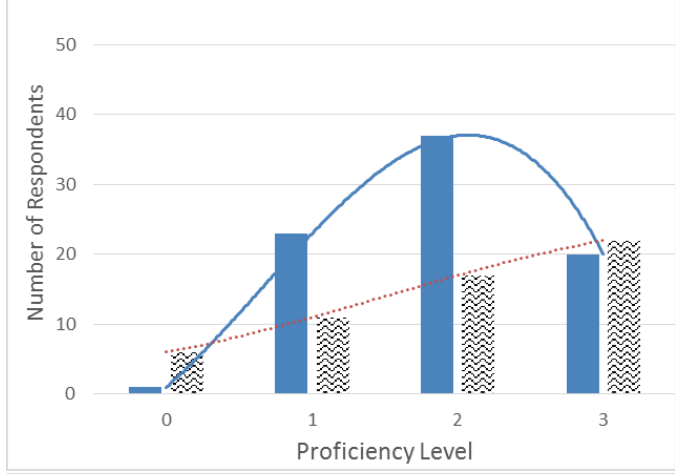

h

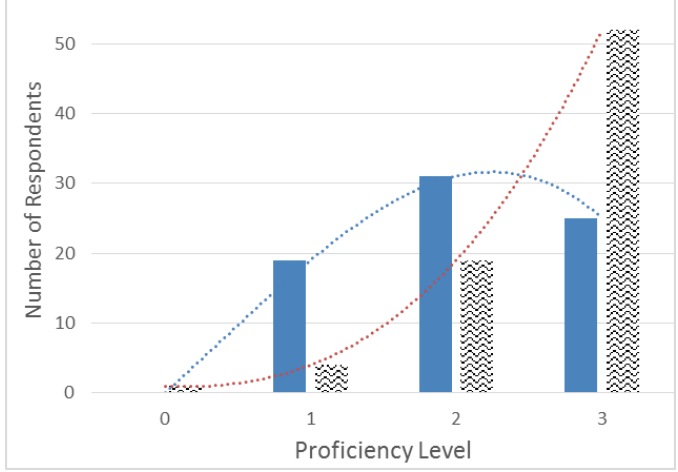

Fig. 2. LCES and CCAT results for the eight mapped questions

Legend: Solid - CCAT; hatched - LCES. Graphs a-h correspond to the attributes: 3) Investigation, 6) Individual and Team work, 7) Communication Skills, 8) Professionalism, 10) Ethics and Equity, 11) Economics and Project management,

12a) Life-long learning, and 12c) Life-long learning respectively. 
Learning however did not receive particularly high ratings; Individual and teamwork and Professionalism were instead the most highly rated attributes.

A more interesting result, however, is that every LCES average response is higher than its mapped CCAT counterpart. Averaging over all LCES responses and all CCAT responses, we find the LCES to give $\sim 15 \%$ higher ratings than the CCAT.

To further explore this, we took our eight paired questions and looked at the distribution of responses, rather than their averages. Figure 2 shows the results for each question, the LCES results have their peak in the highest bin ("Always"), while the CCAT results peak in the second highest ("Accomplished").

Although the LCES and the CCAT are surveying the exact same population - co-op employers of engineering students on work term \#4 or higher during 2014 - there appear to be systematic differences in the responses to the two surveys.

Naively, one might expect employers to have been more critical in the LCES, where they knew their anonymity was secure. A possible explanation for more favourable LCES results is in the stated purpose of the two surveys: employers may be more lenient in their ratings when they believe they are helping us maintain our accreditation, and more strict when they feel they are evaluating a student as part of their degree requirements.

Whatever the explanation for this systematic difference, more work is needed to determine if and how we can combine the results of the CCAT and the LCES.

\section{CONCLUSIONS AND FUTURE WORK}

In this paper we described and compared the two surveys currently in use at UVic to gather employers' assessments of our co-op students. The results we presented were interesting as regards to our employers' opinions, but also pointed to an intriguing difference between the two tools: the LCES gave systematically higher average ratings and a different distribution of responses.

To explore this further, we plan to modify the LCES next term to ask employers for identifying information. If we could pair responses to the LCES and the CCAT that were made by the same employer, that would allow us to better analyze how those responses differ between the two tools. We are also considering holding focus groups with employers to discuss the LCES and gain a better understanding of how employers view the tool and the questions in it.

Co-op employer evaluations are a valuable way to assess our students' development in the attributes. At UVic, we are fortunate to have more than one assessment tool at our disposal; the challenge as always is to deal appropriately with the wealth of data they provide.

\section{Acknowledgements}

MG would like to acknowledge Becca Edwards and Lindsay McCardle from the Technology Integration and Evaluation lab at the University of Victoria for the background they provided on survey analysis, and Rhonda Korol and Vanessa Raber from UVic Cooperative Education Program and Career Services for the information they provided on the CCAT.

\section{References}

[1] Cicek Jillian Seniuk, Labossiere Paul and Mann Danny, "Surveying fourth year engineering student perceptions of graduate attribute competencies," in Proc. CEEA Canadian Engineering Education Conf., (Montreal, QC; 17-20 June 2013), pp 1-7, 2013. Available as of April 23, 2015 from http://library.queensu.ca/ojs/index.php/PCEEA/article/ view/4857/4804

[2] Coolen Anne Marie, "Implementing a CEAB Engineering Graduate Attributes Based Co-op Work Term Curriculum," in Proc. CEEA Canadian Engineering Education Conf., CEEC11, Andy Fisher (ed.) (St. John's, NL; 6-8 June 2011), 2011. Available as of April 23, 2015 from http://library.queensu.ca/ojs/index.php/PCEEA/issue/ view/328

[3] Engineering and Computer Science, Dalhousie University, "Graduate Attributes Self-Assessment and Inventory Tool". Available as of April 23, 2015 from http://egad.engineering.queensu.ca/wp-content/documents/ GASelf-Assessmentedited.pdf

[4] Ferens Ken, "External Assessment of Engineering Programs," in Proc. CEEA Canadian Engineering Education Conf., (Winnipeg, MB; 17-20 June 2012), pp 1-4, 2012. Available as of April 23, 2015 from http://library.queensu.ca/ojs/index.php/PCEEA/article/ view/4670/4652

[5] Parker, W J, Fondacaro, R and Nespoli, O., "Employing Coop Employer Evaluations to Assess Outcomes," in Proc. CEEA Canadian Engineering Education Conf., CEEC11, Andy Fisher (ed.) (St. John's, NL; 6-8 June 2011), pp 1-1, 2011. Available as of April 23, 2015 from http://library.queensu.ca/ojs/index.php/PCEEA/issue/ view/328

[6] Spracklin-Reid Darlene, "Teaching and assessing graduate attributes in Cooperative education," in Proc. CEEA Canadian Engineering Education Conf., (Canmore, AB; 811 June 2014), Paper 063, 2014. Available as of April 23, 2015 from https://ceea2014.files.wordpress.com/2014/06/ ceea2014_submission_63.pdf

[7] Univeristy of Victoria Co-operative Education Program and Career Services, "Student competencies". Available as of April 23, 2015 from http://www.uvic.ca/coopandcareer/ employers/coop/studentskills 